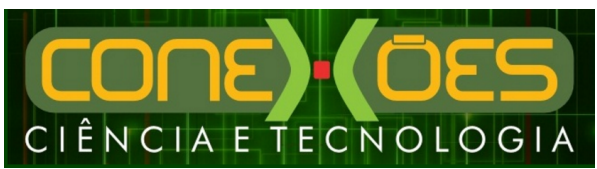

\title{
COBERTURA VEGETAL SOBRE CÉLULA DE ATERRO SANITÁRIO ENCERRADA HÁ VINTE ANOS NO CEARÁ
}

\author{
Gemmelle Oliveira Santos e Maria Vanisse Borges de Matos \\ ${ }^{1}$ Instituto Federal de Educação, Ciência e Tecnologia do Ceará (IFCE), campus de Fortaleza \\ <gemmelle@ifce.edu.br>, <vanisse16@yahoo.com.br>
}

DOI: 10.21439/conexoes.v11i6.891

\begin{abstract}
Resumo. O objetivo da pesquisa foi avaliar a regeneração natural através do levantamento florístico das espécies herbáceas, arbustivas e arbóreas ocorrentes sobre uma célula encerrada de resíduos sólidos urbanos do Aterro Sanitário de Caucaia (ASMOC). O trabalho envolveu (i) contagem e identificação das espécies, (ii) coleta de flores, folhas, sementes para montagem de um catálogo, (iii) comparações visuais entre as espécies encontradas em herbários, (iv) verificação se os exemplares vegetais encontrados na área estudada estão ou não inclusos na lista das espécies vegetais do levantamento florístico do recente Estudo de Impacto Ambiental - EIA da ampliação do ASMOC. Foram identificados vegetais de 22 espécies, com exemplares da Caatinga e de outros biomas. Contribuíram para existência de tal diversidade (i) o tempo de encerramento da célula (aproximadamente 20 anos) e suas múltipas transformações físicas, químicas e biológicas; (ii) a presença de sementes nos resíduos sólidos domiciliares; (iii) a presença de diversas sementes nos solos provenientes das atividades da limpeza urbana realizada em Fortaleza e Caucaia (Ceará), especialmente na poda, raspagem e capina, depositados sobre a célula estudada durante alguns anos; (iv) a presença de remanescentes naturais nos arredores do ASMOC permitindo o aporte de sementes por meios bióticos e abióticos; (v) o transporte de sementes de locais diversos pelo movimento de pessoas e veículos; (vi) a ocorrência de regime de chuvas (média do período) de 1.319 mm anuais no município.
\end{abstract}

Palavras-chaves: Levantamento florístico. Solos de Aterros Sanitários. Resíduos Sólidos Urbanos.

Abstract. The purpose of this study was to evaluate the natural regeneration through the floristic survey of the herbaceous, shrub and tree species occurring in a closed section within the Caucaia municipal solid waste landfill (ASMOC).This work involved (i) a species count and identification; (ii) the collection of flowers, leaves and seeds for a catalog; (iii) visual comparisons between the species found and those kept at a herbarium; (iv) check whether or not the plant specimens found in the studied area are included in the list of vegetal species reported by the floristic survey of the recent Environmental Impact Assessment - EIA for the enlargement of the ASMOC. 23 species of plants were identified, including species of the Caatinga and other biomes. The following factors contributed to such diversity: (i) the time elapsed since the section's closing (about 20 years) and its multiple physical, chemical and biological transformations; (ii) the presence of seeds in the solid waste; (iii) the presence of different seeds in the soil from urban cleaning activities conducted in the cities of Fortaleza and Caucaia (State of Ceara), especially in pruning, weeding and scraping wastes disposed of in the studied landfill section along several years; (iv) the presence of remaining natural areas on the outskirts of ASMOC allowing the supply of seeds by biotic and abiotic means; (v) seed transport from various locations by people and vehicles; (vi) a local rainfall regimen of $1,319 \mathrm{~mm}$ per year (average for that period).

Keywords: Vegetal survey. Landfill Soil. Municipal Solid Waste. 


\section{INTRODUÇÃO}

A revegetação dos aterros sanitários encerrados tem vários benefícios: elimina a proliferação de vetores e odores; ajuda a proteger o aterro contra a ação de processos erosivos; minimiza o fluxo de gás para a atmosfera e minimiza a infiltração de águas pluviais; estabiliza os taludes e proporciona paisagem agradável (KUMARI; PANDEY; RAI, 2013), principalmente se realizada com o plantio de gramíneas (MEINERZ et al. 2009), que ainda produzem um bom efeito visual (BARROS, 2011) e reduzem a fuga dos gases (SANTOS, 2012).

Embora estejam claros os benefícios, Rahman et al. (2013) afirmam que pouco se sabe sobre as comunidades de plantas que melhor se adaptam a restauração de aterros sanitários encerrados, pois é necessário alto nível de conhecimento sobre a estrutura das espécies a serem utilizadas. Além disso, o solo do aterro é pobre, pois na maioria das vezes são importados de várias fontes, apresentando substrato grosseiro e uma alta concentração de gás. Assim, revegetar um aterro sanitário não é tarefa simples, pois há deficiência de nutrientes, alta declividade, e dificuldade em selecionar espécies e métodos para a revegetação (SOUZA, 2007).

Segundo United States Environmental Protection Agency - USEPA (2005), a migração dos gases de aterros por camadas superficiais do solo tende a matar o sistema radicular, resultando em estresse vegetativo visível ao longo do caminho da migração. Para Ministry of Environment of the British Columbia (2010), o estresse vegetativo ocorre porque as raízes das plantas são privadas de oxigênio e porque o gás carrega componentes que são diretamente tóxicos para as plantas.

Oliveira (2004) esclarece que as plantas arbustivas e arbóreas apresentam maior dificuldade de se estabelecerem sobre os aterros sanitários, pois possuem raízes mais profundas e desta forma sofrem maior influência do ambiente. Muitas observações sobre o crescimento da vegetação em camadas superficiais do solo de aterro sanitário mostram que o crescimento da planta é severamente inibido pela presença de concentrações elevadas de gases na zona das raízes (XIAOLI et al., 2010).

Além desses aspectos, as áreas que receberam resíduos sólidos geralmente perderam solo, vegetação e fauna e os distúrbios sofridos em função das atividades de recebimento e armazenamento de resíduos impedem a regeneração natural da área (SOUZA, 2007), sendo fundamental a atuação humana no processo de recuperação ambiental (SANTOS, 2012).

Pelo exposto, observa-se que existem muitas dificuldades técnicas para a reabilitação ambiental dos ater- ros sanitários, pois as características biológicas, climáticas e ambientais intrínsecas ao local de estudo exercem forte influência sobre o processo, além do fato de existirem nos resíduos sólidos poluentes como gases e metais tóxicos que deixam o ambiente ainda mais adverso (LONDE; BITAR, 2011).

Contrariando parte dos relatos da literatura, vem se observando não só a sobrevivência como também o desenvolvimento da cobertura vegetal sobre células de resíduos encerradas do Aterro Sanitário de Caucaia (ASMOC), Região Metropolitana de Fortaleza (CE), o que despertou o interesse dos pesquisadores em conhecer as condições ambientais locais que estão favorecendo esse processo.

O objetivo da pesquisa foi avaliar a regeneração natural através do levantamento florístico das espécies herbáceas, arbustivas e arbóreas ocorrentes em uma área de 2,8 hectares, pois além de localmente inédito, os resultados servem de base para o desenvolvimento de projetos de recuperação ambiental mais adequados para a realidade do Estado do Ceará.

\section{MATERIAIS E MÉTODOS}

Este trabalho foi realizado no Aterro Sanitário de Caucaia (ASMOC), que dista aproximadamente $30 \mathrm{~km}$ de Fortaleza, capital do Estado do Ceará, Nordeste, Brasil.

Do ponto de vista ambiental, o ASMOC encontra-se localizado na Formação Barreiras, na unidade do Glacis Pré-Litorâneo, onde o relevo apresenta-se predominantemente plano, com trechos suave ondulado (DOMINGOS, 2007). Ainda segundo o autor as condições climáticas do referido município variam entre úmidas e subúmidas com precipitações irregulares no decorrer do ano.

A área do ASMOC destinada à disposição de resíduos sólidos tem 78,47 hectares e até outubro de 2014, já tinha recebido aproximadamente 18 milhões de toneladas. Em 2014, especificamente, o aterro sanitário recebeu 2.261.740,84 toneladas de diversas origens.

A célula estudada tem 2,8 hectares e 9 metros de altura (localização geográfica: 347’35.53" S; $38^{\circ}$ 40'09.43” W). É uma das mais antigas do aterro sanitário e foi encerrada há aproximadamente 20 anos. Sobre ela observa-se o surgimento natural de vegetação herbácea, arbustiva e arbórea (Fotos $1 \mathrm{e} 2$ ).

Para entender o processo de revegetação foi realizado levantamento florístico com (i) contagem e identificação das espécies vegetais (LORENZI, 1998; ASSOCIAÇÃO CAATINGA, 2011; FUNDAÇÃO BRASIL 
COBERTURA VEGETAL SOBRE CÉLULA DE ATERRO SANITÁRIO ENCERRADA HÁ VINTE ANOS NO CEARÁ

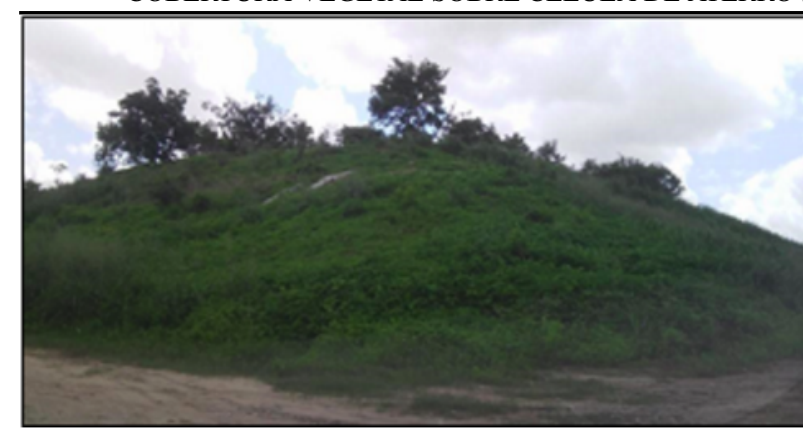

Figura 1: Vista geral da célula estudada com a presença de vegetação.

Fonte: Autores (2015)

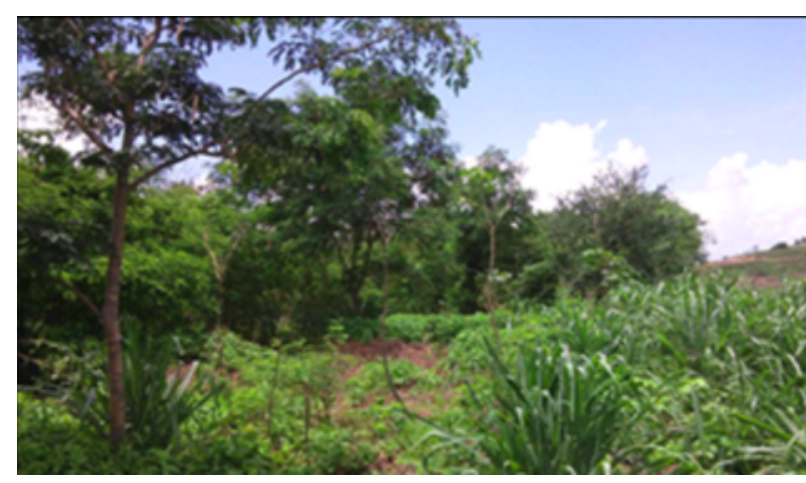

Figura 2: Vista geral da vegetação na célula estudada.

Fonte: Autores (2015)

CIDADÃO, 2012) (ii) coleta de flores, folhas, sementes e afins para montagem de um catálogo e (iii) comparações visuais entre as espécies vegetais encontradas em relação aos registros de herbários digitais, sob a supervisão de um técnico do Parque Botânico do Ceará e verificação se os exemplares vegetais encontrados na área estudada estão ou não inclusos na lista das espécies vegetais do levantamento florístico do recente Estudo de Impacto Ambiental - EIA da ampliação do ASMOC (LIMA et al., 2011).

Também foi realizada a medição do Diâmetro à Altura do Peito - DAP, pois este parâmetro permite ampliar a compreensão sobre nível de desenvolvimento vegetal (SOCIEDADE BRASILEIRA DE BOTÂNICA DO BRASIL, 2013).

\section{RESULTADOS E DISCUSSÃO}

A célula estudada apresenta vegetais pertencentes ao estrato herbáceo, arbustivo e arbóreo. Foram identificados vegetais de 22 espécies (Figura 3), com exemplares da Caatinga e de outros biomas (Tabela 1).

Os processos que devem ter contribuído para existência de tal diversidade foram: (i) o tempo de encerramento da célula (aproximadamente 20 anos) e suas múltipas transformações físicas, químicas e biológicas; (ii) a presença de sementes nos resíduos sólidos domiciliares; (iii) a presença de diversas sementes nos solos provenientes das atividades da limpeza urbana realizada em Fortaleza e Caucaia, especialmente na poda, raspagem e capina, depositados sobre a célula estudada durante alguns anos; (iv) a presença de remanescentes naturais nos arredores do ASMOC e o transporte de sementes pela ação dos ventos, chuvas e animais (pássaros, morcegos, abelhas etc); (v) o transporte de sementes de locais diversos pelo movimento de pessoas e veículos; (vi) a ocorrência de um regime de chuvas (média do período) de $1.319 \mathrm{~mm}$ anuais no município.

\section{Do estrato herbáceo}

O extrato herbáceo (grupo de plantas folhosas, não lenhosas, de pequeno porte e que vivem próximas ao solo), a exemplo das ervas e gramíneas, foi o extrato com maior predominância. A majoritária presença do estrato herbáceo na área estudada pode ser explicada pelas características inerentes aos indivíduos que compõem tal estrato: rápido desenvolvimento, período de fertilidade longo, geração de um grande número de descendentes, mais de uma alternativa de reprodução, sistemas de autopolinização e polinização cruzada, facilidade de adaptação a condições diversas, baixa exigência nutricional, sementes pequenas de fácil dispersão e dispersão por formas diversas (fauna, água, vento). A seguir, descrevem-se as principais espécies identificadas na célula estudada.

- Nome popular (Chanana), Nome científico (Turnera uniflora)

É uma planta herbácea que pertence à família Turneraceae. Há várias referências sobre seu uso na medicina popular (BARBOSA; SILVA; AGRA, 2007; MADALENO, 2011; ANDRADE et al., 2012). Conforme Lorenzi (1998) é cultivada como ornamental, contudo é muito persistente tornando-se planta daninha, pois se infestam em pastagens, beiras de estradas e terrenos baldios. A Chanana (Figura 3- A) consta na lista das espécies vegetais existentes no levantamento florístico do recente Estudo de Impacto Ambiental - EIA da am- 
COBERTURA VEGETAL SOBRE CÉLULA DE ATERRO SANITÁRIO ENCERRADA HÁ VINTE ANOS NO CEARÁ

Tabela 1: Lista das espécies vegetais encontradas sobre a célula estudada do ASMOC.

\begin{tabular}{c|c|c|c}
\hline Nome popular & Nome científico & Nome popular & Nome científico \\
\hline Chanana & Turnera uniflora & Catingueira & Caesalpinia pyramidalis \\
\hline Salsa & Ipomoea asarifolia & Angico branco & Anadenanthera colubrina \\
\hline Bucha Vegetal & Luffa cylindrica & Acácia Amarela & Acacia farnesiana \\
\hline Milho de Cobra & Dracontium loretense & Mutamba & Guazuma ulmifolia \\
\hline Capim Elefante & Pennisetum prunifera & Jucá & Caesalpinia ferrea \\
\hline Urtiga & Pourouma cinerascens & Alfavacão & Ocimum gratissimum \\
\hline Ciúme & Calotropis procera & Acerola & Malpighia emarginata \\
\hline Mamona & Ricinus communis & Feijão Bravo & Capparis flexuosa \\
\hline Jurema preta & Mimosa tenuiflora & Mata-pasto & Senna occidentalis \\
\hline Cajá & Spondias mombin & Carnaúba & Copernicia prunifera \\
\hline Mororó & Bauhinia forticata & Mandacaru & Cereus jamacaru \\
\hline Leucena & Leucaena leucocephala & &
\end{tabular}

Fonte: Autores (2015).

pliação do ASMOC.

- Nome popular (Salsa), Nome científico (Ipomoea asarifolia)

É uma planta herbácea que pertence à família Convolvulaceae, com ocorrência em todos os estados das regiões Norte e Nordeste. A Salsa (Figura 3- B) consta na lista dos gêneros vegetais existentes do levantamento florístico do recente Estudo de Impacto Ambiental EIA da ampliação do ASMOC.

O estudo desenvolvido por Bonatto et al. (2005 identificou a presença da Salsa no Lixão de Aurá (Belém-PA). Os autores relatam ainda que, entre todas as plantas utilizadas na pesquisa, a Salsa teve o mais alto potencial de fitorremediação, apresentando boa sanidade e grande desenvolvimento de suas raízes fasciculadas no ponto de maior concentração de metais pesados (antiga saída de chorume).

Carneiro e Irgang (1999), também identificaram a presença da Salsa no aterro sanitário da zona norte da cidade de Porto Alegre. Os autores destacam que a família Poaceae, possui maior número de espécies em ambientes antropizados.

Andrade (2009) identificou a vegetação presente no aterro Invernadinha, município de Passo Fundo/RS, onde a Salsa foi identificada em cinco anos, não consecutivos, do período compreendido entre os anos 2000 e 2008. Segundo o autor, trata-se de um vegetal persistente ou de boa adaptação à área.

- Nome popular (Bucha Vegetal), Nome científico (Luffa cylindrica)

É uma planta pertencente à família Cucurbitaceae. Trata-se de uma espécie invasora proveniente do Nor- deste do Brasil (MAROUELLI; SILVA; LOPES, 2013). Sobre as plantas invasoras Santana e Encinas (2008), ao revisarem alguns autores, apresentam as seguintes características principais: alta taxa de crescimento relativo, grande produção de sementes pequenas e de fácil dispersão, alta longevidade das sementes no solo, alta taxa de germinação dessas sementes, maturação precoce das plantas já estabelecidas, floração e frutificação mais prolongadas, alto potencial reprodutivo por brotação, pioneirismo, alelopatia e ausência de inimigos naturais.

Na célula estudada, a Bucha Vegetal (Figura 3 C) desenvolveu-se mantendo a vegetação arbustivoarbórea como suporte e por ser uma espécie que se reproduz com grande facilidade foi observada em toda a célula. A Bucha Vegetal não consta na lista das espécies vegetais existentes do levantamento florístico do recente Estudo de Impacto Ambiental - EIA da ampliação do ASMOC.

Santana e Encinas (2008) observaram que, em áreas perturbadas antropicamente, há uma crescente disseminação das espécies exóticas. Quando os autores compararam a área adjacente ao aterro do Jockey Club de Brasília (BSB) com uma área controle, observaram a presença de 10 espécies exóticas ao Cerrado na primeira área e apenas 3 espécies na segunda área. Quando estudaram o Aterro Sanitário de Goiânia (GYN) e sua área controle, a diferença foi ainda mais significativa: observaram 12 espécies exóticas na primeira área e nenhuma na segunda área.

- Nome popular (Milho de Cobra), Nome científico (Dracontium loretense) 
É uma planta herbácea característica de florestas primárias ou secundárias pertencente à família Araceae. As populações desta espécie são escassas e muitas vezes são encontradas plantas individuais isoladas, como na área estudada. Há referências quanto ao seu uso na medicina popular (GONZÁLES et al. 2002, LOVERA; BONILLA; HIDALGO, 2006).

O Milho de Cobra (Figura 3- D) não consta na lista das espécies vegetais existentes do levantamento florístico do recente Estudo de Impacto Ambiental - EIA da ampliação do ASMOC.

- Nome popular (Capim Elefante), Nome científico (Pennisetum prunifera)

É uma gramínea forrageira da família Poaceae (SOBRINHO et al. 2008). Na área estudada observou-se grande predominância do Capim Elefante, o que é vantajoso para o processo de recuperação ambiental, pois conforme Souza (2007), enquanto as gramíneas desempenham o papel de preparação do solo, as leguminosas fixam nitrogênio e desse modo, ambas melhoram as condições locais para a introdução futura de outras espécies mais nobres. Tendo as condições do solo melhoradas, será possível pensar no restabelecimento da vegetação original daquela área, o que é o principal objetivo de se promover a recuperação de áreas degradadas.

O Capim Elefante (Figura 3- E) não consta na lista das espécies vegetais existentes do levantamento florístico do recente Estudo de Impacto Ambiental - EIA da ampliação do ASMOC. Andrade (2009) identificou-o no aterro Invernadinha, município de Passo Fundo/RS. Segundo o autor, trata-se de um vegetal persistente ou de boa adaptação à área.

- Nome popular (Urtiga), Nome científico (Pourouma cinerascens)

É uma erva que pertence a família Urticaceae, ocorrendo em áreas degradadas, terrenos baldios, ao longo de rodovias e restingas. A Urtiga (Figura 3 - F) não consta na lista das espécies vegetais existentes do levantamento florístico do recente Estudo de Impacto Ambiental - EIA da ampliação do ASMOC.

- Nome popular (Ciúme), Nome científico (Calotropis procera)

Pertence à família Apocynaceae, sendo nativa da África, Península Arábica e Sudoeste da Ásia. Segundo Souto et al. (2008), a referida espécie (Figura 3- G) desenvolve-se bem em solos arenosos, degradados e em locais com baixo índice pluviométrico, resistindo à seca, permanecendo verde e exuberante durante todo o ano.

A Ciúme consta na lista das espécies vegetais exis- tentes do levantamento florístico do recente Estudo de Impacto Ambiental - EIA da ampliação do ASMOC.

- Nome popular (Mamona), Nome científico (Ricinus communis)

A Mamona (Figura 3- H) é planta oleaginosa da família Euphorbiaceae, originária do leste do continente Africano. A Mamona encontra-se difundida nos estados da região Nordeste, principalmente na zona semiárida, devido ao seu alto grau de tolerância a déficit de umidade no solo e a temperaturas elevadas, onde aparece como produto de importância social e econômica.

No ASMOC observou-se grande predominância da Mamona. Ela consta na lista das espécies vegetais existentes do levantamento florístico do recente Estudo de Impacto Ambiental - EIA da ampliação do ASMOC.

Segundo Andrade (2009), a mamona está entre as espécies que apareceram de forma espontânea no aterro de Invernadinha no município de Passo Fundo-RS, o autor destaca ainda que o aterro de Invernadinha, o qual foi encerrado também há aproximadamente 20 anos, está em processo de recuperação ambiental natural. Porém, em poucas áreas há apenas presença de vegetação arbustiva e gramínea, sendo nestes pontos necessário a intervenção humana.

A referida espécie também está presente em outras áreas de disposição de resíduos (CARNEIRO; IRGANG, 1999; SANTANA; ENCINAS, 2008; CAVALHEIRO et al. 2014). Há referências quanto ao seu uso na medicina popular (MADALENO, 2011).

\section{Dos estratos arbustivo e arbóreo}

- Nome popular (Jurema preta), Nome científico (Mimosa tenuiflora)

É uma árvore nativa de pequeno porte pertencente à família Leguminosae e que predomina na Caatinga e Cerrado. Para Bezerra (2008), a Jurema Preta (Figura 3 - I) é uma espécie muito importante para a manutenção da biodiversidade e funcionamento dos ecossistemas, tem crescimento rápido e sua capacidade de rebrota faz com que seja importante na restauração de áreas degradadas. É uma espécie indicadora de uma sucessão progressiva e conta com raízes de alta capacidade de penetração em terrenos compactados. Participa da recuperação do teor de nitrogênio do solo, preparando-o para o aparecimento de outras plantas mais exigentes.

A Jurema Preta consta na lista das espécies vegetais existentes do levantamento florístico do recente Estudo de Impacto Ambiental - EIA da ampliação do ASMOC. Na célula estudada foram encontrados 05 indivíduos da espécie com diâmetros variando entre 6 a $30 \mathrm{~cm}$. 
COBERTURA VEGETAL SOBRE CÉLULA DE ATERRO SANITÁRIO ENCERRADA HÁ VINTE ANOS NO CEARÁ

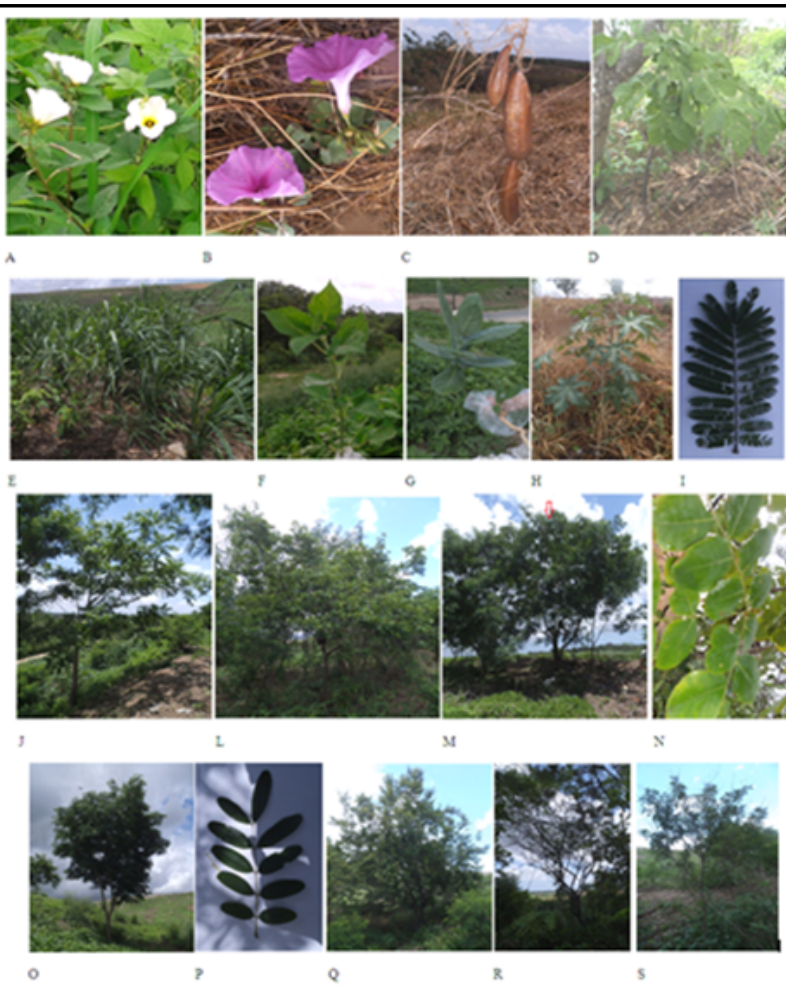

Figura 3: Catálogo de algumas espécies encontradas no aterro sanitário

Fonte: Autores (2015)

A Jurema preta é uma espécie usada na fitorremediação de áreas contaminadas por metais pesados, no trabalho de Ismael, Leite e Silva (2013), no lixão de Pombal-PB, está entre as espécies recomendas para a recuperação ambiental da área. Também está presente em outras áreas de disposição de resíduos (ANDRADE. 2005; ISMAEL; LEITE; SILVA, 2013, CARNEIRO; IRGANG, 1999; ANDRADE, 2009).

- Nome popular (Cajá), Nome científico (Spondias mombin)

É uma árvore (Figura 3- J) frutífera típica de zonas úmidas e subúmidas pertencente à família Anacardiaceae. A planta é semidecídua e encontrada nas formações secundárias, onde regenera espontaneamente tanto a partir de sementes como de estacas e raízes. Produz anualmente grande quantidade de sementes viáveis, amplamente disseminadas pela fauna (LORENZI 1998).

A Cajazeira não consta ou não na lista das espécies vegetais existentes do levantamento florístico do recente Estudo de Impacto Ambiental - EIA da ampliação do ASMOC.
- Nome popular (Mororó), Nome científico (Bauhinia forticata)

É uma planta (Figura 3 - L) que pertence à família Leguminosae, nativa do sudeste do Brasil, mas também encontrada em áreas da região Nordeste. O Mororó consta na lista das espécies vegetais existentes do levantamento florístico do recente Estudo de Impacto Ambiental - EIA da ampliação do ASMOC. Na célula estudada foram identificados 04 indivíduos com diâmetro entre 8 e $10 \mathrm{~cm}$. Está presente em outras áreas de disposição de resíduos (RESENDE et al., 2015, BARROS, 2011).

- Nome popular (Leucena), Nome científico (Leucaena leucocephala)

A espécie é exótica e é um arbusto ou árvore que mede entre 5 e 10 metros de altura, originária da América Central e pertence à família Leguminosae. A Leucena (Figura 3- M) é utilizada para a recuperação da cobertura vegetal e reabilitação de áreas degradadas (COSTA; DURIGAN, 2010). A Leucena não consta na lista das espécies vegetais existentes do levantamento florístico do recente Estudo de Impacto Ambiental EIA da ampliação do ASMOC.

$\mathrm{Na}$ célula estudada foram identificados 10 Leucenas com diâmetros entre 7 e $11 \mathrm{~cm}$. A Leucena (espécie leucocephala), também foi identificada no estudo desenvolvido por Santana e Encinas (2008), nas áreas adjacentes ao aterro do Jockey Club de Brasília e por Andrade (2005), na revegetação da cobertura do aterro Santo Amaro (SP).

Santana e Encinas (2008) concluem que a presença de depósitos de resíduos domiciliares aumenta a incidência de espécies exóticas arbóreas em relação às espécies nativas. Algumas pesquisas citadas pelos autores deixaram evidente que a presença de um único indivíduo de planta exótica poderá ser suficiente em longo e médio prazo para a disseminação da espécie em ambientes naturais.

- Nome popular (Catingueira), Nome científico (Caesalpinia pyramidalis)

Segundo a ASSOCIAÇÃO CAATINGA (2011) é uma árvore nativa do bioma Caatinga pertencente à família Leguminosae. É uma espécie (Figura 3- N) que consta na lista das espécies vegetais existentes do levantamento florístico do recente Estudo de Impacto Ambiental - EIA da ampliação do ASMOC. Está presente em outras áreas de disposição de resíduos (ISMAEL; LEITE; SILVA, 2013).

- Nome popular (Angico branco), Nome científico (Anadenanthera colubrina)

O Angico branco (Figura 3- O) pertence à família 
Leguminosae e é uma planta extremamente ornamental e indicada também para plantios mistos em áreas degradadas (LORENZI, 1998). O Angico branco consta na lista das espécies vegetais existentes do levantamento florístico do recente Estudo de Impacto Ambiental EIA da ampliação do ASMOC.

O Angico branco é uma espécie recomendada para a fitorremediação de áreas contaminadas por substâncias inorgânicas, como metais pesados. Está presente nos planos de recuperação ambiental para a área do lixão de Pombal-PB (ISMAEL; LEITE; SILVA, 2013)) e do aterro sanitário de Bauru-SP (EMDURB, 2010).

- Nome popular (Acácia amarela), Nome científico (Acacia farnesiana)

Trata-se de um arbusto ou árvore pertencente à família Leguminosae. É resistente ao fogo e usada para o reflorestamento de terras áridas degradadas devido a sua boa adaptação em ambientes áridos e semiáridos (ROCHA et al., 2012).

A Acácia amarela (Figura 3- P) não consta na lista das espécies vegetais existentes do levantamento florístico do recente Estudo de Impacto Ambiental - EIA da ampliação do ASMOC. Na célula estudada foram identificados 05 indivíduos da espécie com diâmetro entre 10 e $19 \mathrm{~cm}$.

O estudo desenvolvido por Santana e Encinas (2008) identificou a presença do gênero Acácia (espécie mearnsii) nas áreas adjacentes ao aterro do Jockey Club de Brasília, a referida espécie também foi sugerida por Meinerz et al. (2009), para recuperação paisagística do Aterro Sanitário de Toledo, segundo os autores é uma importante espécie para restauração de ambientes degradados, a Acacia mearnsii tem a capacidade de formar simbiose com fungos ectomicorrízicos (fECMs), que auxiliam o crescimento das plantas através do aumento na absorção de nutrientes e água, conferindo também maior resistência aos patógenos da raiz e às condições ambientais adversas.

- Nome popular (Mutamba), Nome científico (Guazuma ulmifolia)

É uma árvore característica de estágios iniciais de sucessão, sendo de rápido crescimento e pertencente à família Malvaceae. A Mutamba (Figura 3-Q) consta na lista das espécies vegetais existentes do levantamento florístico do recente Estudo de Impacto Ambiental EIA da ampliação do ASMOC. Na célula estudada foram identificados 02 indivíduos com 09 e $11 \mathrm{~cm}$ de diâmetro.

A Mutamba está presente em outras áreas de disposição de resíduos (RESENDE et al., 2015). Souza (2007), ao exemplificar as espécies pioneiras utiliza- das na recomposição florestal de áreas degradadas, cita a Guazuma ulmilolia (Mutamba). Cita ainda dois gêneros encontrados nesta pesquisa: Acacia (espécie glomearosa) e Mimosa (espécie scabrella). Com relação às espécies definitivas, o autor citou os gêneros: Piptadenia (espécies macrocarpa e gonocantha) e Caesalpinia (espécie echinata).

- Nome popular (Jucá), Nome científico (Caesalpinia ferrea)

Trata-se de uma árvore nativa (Figura 3 - R), pertencente à família Leguminosae, com ocorrência principalmente na Caatinga. O Jucá consta na lista das espécies vegetais existentes do levantamento florístico do recente Estudo de Impacto Ambiental - EIA da ampliação do ASMOC. Na célula estudada foi identificado 01 indivíduo com $16 \mathrm{~cm}$ de diâmetro.

O jucá foi uma das espécies que apontou melhor desenvolvimento na requalificação dos lixões e aterros desativados do município de São Paulo (BARROS, 2011), notadamente por ser uma espécie que se adapta a solos que sofreram perturbações e que apresentam baixa fertilidade, característica das espécies da família Leguminosae.

- Nome popular (Alfavacão), Nome científico (Ocimum gratissimum)

É uma planta (Figura 3 - S) pertencente à família Labiatae, e originária da Asia e África e muito comum no território brasileiro (LORENZI; MATOS, 2008). O Alfavacão não consta na lista das espécies vegetais existentes do levantamento florístico do recente Estudo de Impacto Ambiental - EIA da ampliação do ASMOC. Na célula estudada do ASMOC foi identificado 01 indivíduo. Está presente em outras áreas de disposição de resíduos (CAVALHEIRO et al., 2014; ANDRADE, 2009).

- Nome popular (Acerola), Nome científico (Malpighia emarginata)

É uma planta pertencente à família Malpighiaceae, sendo nativa do Caribe, América Central e porção norte da América do Sul. Na célula estudada do ASMOC foi identificado 01 indivíduo. Tal espécie não consta na lista das espécies vegetais existentes do levantamento florístico do recente Estudo de Impacto Ambiental EIA da ampliação do ASMOC.

- Nome popular (Feijão bravo), Nome científico (Capparis flexuosa)

O Feijão bravo, segundo a Fundação Brasil Cidadão (2012), é nativo, de pequeno porte, pertencente à família Capparaceae e muito comum na Caatinga. No ASMOC foram identificados 02 indivíduos, sendo que seus diâmetros não foram mensurados, pois as plantas 
são muito jovens. O Feijão bravo não consta na lista das espécies vegetais existentes do levantamento florístico do recente Estudo de Impacto Ambiental - EIA da ampliação do ASMOC.

A referida espécie é classificada no trabalho de Bonatto et al. (2005), como uma planta de alto potencial de fitorremediação, muito suscetível à adsorção de metais e esta fitoextração e fitoestabilização a torna uma espécie importante para a remediação de locais poluídos, como áreas de disposição de resíduos sólidos encerradas.

Segundo Espíndola, Almeida e Guerra (2004), o Feijão Bravo também é uma leguminosa adaptada a condições de reduzida umidade do solo e baixa fertilidade. Entende-se ainda do autor que, o uso tal leguminosa tem efeito positivo nas características químicas do solo, especialmente no aumento linear dos teores de nitrogênio, e que o Feijão Bravo está na lista de leguminosas utilizadas para adubação verde em unidades de produção agroecológica.

- Nome popular (Mata-pasto), Nome científico (Senna occidentalis)

A planta pertence à família Leguminosae, subarbustiva, nativa das Américas e distribuída em regiões tropicais ao redor do mundo, sendo frequentemente encontrada contaminando pastos e culturas de cereais. Na célula estudada foi identificado 01 indivíduo da espécie.

O Mata-pasto não consta na lista das espécies vegetais existentes do levantamento florístico do recente Estudo de Impacto Ambiental - EIA da ampliação do ASMOC. Está presente em áreas de disposição de resíduos (CARNEIRO; IRGANG, 1999, CAVALHEIRO et al. 2014; ANDRADE, 2009).

- Nome popular (Carnaúba), Nome científico (Copernicia prunifera)

A Carnaúba, típica do Nordeste brasileiro pertence à família Arecaceae. A Carnaúba tem grande potencial paisagístico, possui celulose de qualidade superior para fabricação de papel e sua madeira é empregada para diversos usos. As folhas, depois de secas, são utilizadas na confecção de esteiras, chapéus e outros artefatos (ARRUDA; CALBO, 2004).

Na célula estudada do ASMOC foi identificado 01 indivíduo jovem. A Carnaúba consta na lista das espécies vegetais existentes do levantamento florístico do recente Estudo de Impacto Ambiental - EIA da ampliação do ASMOC.

- Nome popular (Mandacaru), Nome científico (Cereus jamacaru)

O Mandacaru é um vegetal nativo da Caatinga que pertence à família Cactaceae. É adaptado as condições climáticas do semiárido brasileiro, sendo encontrado em todo o Nordeste e no norte de Minas Gerais. Na célula estudada, foram identificados vários indivíduos da espécie, não sendo possível medir seu diâmetro pela quantidade de espinhos.

O Mandacaru é uma espécie indicadora de nível de sucessão ecológica primária, sobrevive nos piores tipos de solo e sobrevive a longos períodos de estiagem, sendo utilizado como alternativas nos períodos de secas prolongadas, como um dos principais suportes forrageiros dos ruminantes. Também é utilizado na indústria alimentícia e como planta medicinal e ornamental.

O Mandacaru consta na lista das espécies vegetais existentes do levantamento florístico do recente Estudo de Impacto Ambiental - EIA da ampliação do ASMOC. Está presente em outras áreas de disposição de resíduos (ISMAEL; LEITE; SILVA, 2013).

\section{CONCLUSÕES}

Predominou a família das leguminosas na área estudada ( 8 de 22 espécies encontradas), concordando com as recomendações existentes nos planos de recuperação ambiental de aterros sanitários.

A vegetação existente é composta por espécies cujas sementes são provenientes de diversas origens: restos de alimentos, remanescentes naturais dos arredores do aterro sanitário, que foram transportadas pelo movimento de pessoas, veículos, pela ação dos ventos, chuvas e também vindas com o próprio resíduo sólido.

Algumas espécies indicam que a célula está passando por uma sucessão ecológica que no futuro poderá assemelhar a área do aterro, exceto na topografia, com a paisagem natural vizinha.

A diversidade de solos, resíduos e materiais que chegam ao aterro sanitário aparentemente permitiu aumentar a diversidade das espécies vegetais em relação à vizinhança.

O histórico ato de cobrir a célula estudada com resíduos e solos provenientes das atividades da limpeza urbana, especialmente poda, raspagem e capina, provavelmente subsidiou o misto processo de formação da vegetação encontrada.

As espécies estão bem distribuídas ao longo da cobertura da área estudada, ou seja, não foram verificadas "ilhas de vegetação".

\section{REFERÊNCIAS}

ANDRADE, J. C. M. e. Fitotransporte de metais em espécies arbóreas e arbustivas em aterro de resíduos sólidos urbanos. 263 p. Tese (Doutorado em 
COBERTURA VEGETAL SOBRE CÉLULA DE ATERRO SANITÁRIO ENCERRADA HÁ VINTE ANOS NO CEARÁ

Engenharia Civil) — Pós-Graduação em Engenharia Civil. Universidade Federal do Rio de Janeiro, Rio de Janeiro, 2005.

ANDRADE, L. C. d. Diagnóstico do solo, água e vegetação de uma antiga área de disposição de res íduos sólidos urbanos. 162 p. - Trabalho de Conclusão de Curso (Graduação em Engenharia Ambiental), Faculdade de Engenharia e Arquitetura, Universidade de Passo Fundo, Passo Fundo, 2009.

ANDRADE, S. E. O. de; MARACAJÁ, P. B.; SILVA, R. A. da; FREIRES, G. F.; PEREIRA, A. de M. Estudo etnobotânico de plantas medicinais na comunidade Várzea Comprida dos Oliveiras, Pombal, Paraíba, Brasil. Revista Verde de Agroecologia e Desenvolvimento Sustentável, v. 7, n. 3, p. 46-52, 2012.

ARRUDA, G. M. T.; CALBO, M. E. R. Efeitos da inundação no crescimento, trocas gasosas e porosidade radicular da carnaúba (copernicia prunifera (mill.) H.E Moore). Acta Botanica Brasilica, v. 18, n. 2, p. 219-224, 2004.

ASSOCIAÇÃO CAATINGA. Manual Técnico: conhecendo e produzindo sementes e mudas da Caatinga. Fortaleza: Associação Caatinga. Associação APNE/CNIP, 2011. 60 p.

BARBOSA, D. d. A.; SILVA, K. N.; AGRA, M. d. F. Comparative and pharmacobotanical study of the leaves of turnera chamaedrifolia cambess. and turnera subulata sm.(turneraceae). Revista Brasileira de Farmacognosia, SciELO Brasil, v. 17, n. 3, p. 396-413, 2007.

BARROS, L. H. d. S. Requalificação dos aterros desativados (brownfields) no Município de São Paulo: Parques (greenfields) Raposo Tavares e Jardim Primavera. 430 p. Tese (Doutorado) Universidade de São Paulo, 2011.

BEZERRA, D. A. Estudo fitoquímico, bromatológico e microbiológico de mimosa tenuiflora (wild) poiret e piptadenia stipulacea (benth) ducke. Campina Grande, PB. apresentada como dissertação de mestrado, Departamento de Zootecnia, UFCG, p. 62, 2008.

BONATTO, F. S. et al. Quantificação de metais pesados em plantas potencialmentefitorremediadorasnodepósito de resíduos sólidos do Aurá-Belém/PA. In:

CONGRESSO DE ECOLOGIA DO BRASIL,7.

Caxambu: Anais...Caxambu: SEB, 2005.
CARNEIRO, A. M.; IRGANG, B. E. Colonização vegetal em aterro sanitário na região peri-urbana de porto alegre, RS, Brasil. Revista da Faculdade de Zootecnia, Veterinária e Agronomia, v. 5, n. 1, p. 1 11, 1999.

CAVALHEIRO, T. L. et al. Avaliação da eficiência daswetlandsnaturais no pós-tratamento do lixiviado no aterro sanitário da caximba. In: SEMINÁRIO SOBRE GESTÃO DE RECURSOS HÍDRICOS, 4. Curitiba, PR, Brasil. Campos dos Goytacazes: IFF, 2014.

COSTA, J. N. M. N. da; DURIGAN, G. Leucaena leucocephala (lam.) de Wit (fabaceae): invasora ou ruderal? Revista Árvore, v. 34, n. 5, p. 825-833, 2010.

DOMINGOS, C. Geoprocessamento na Escolha de Sistemas Ambientais para Aterros Sanitários na Região Metrpolitana de Fortaleza-CE. Dissertação (Mestrado em Geografia) - Mestrado Acadêmico em Geografia. Universidade do Estado do Ceará, Fortaleza, 2007.

EMPRESA MUNICIPAL DE DESENVOLVIMENTO URBANO E RURAL DE BAURU - EMDURB.

Ampliação do atual aterro sanitário do município de Bauru. Bauru: EMDURB, 2010.

ESPÍNDOLA, J. d. A.; ALMEIDA, D. de; GUERRA, J. Estratégias para utilização de leguminosas para adubação verde em unidades de produção agroecológica. Embrapa Agrobiologia-Documentos (INFOTECA-E), Seropédica: Embrapa Agrobiologia, p. 24, 2004.

FUNDAÇÃO BRASIL CIDADÃO. Guia de plantas visitadas por abelhas na caatinga. Fortaleza: editora FBC, p. 191, 2012.

GONZÁLES, R. I. et al. Estudio Clínico Fase II del Dracontium loretense K. Krause (ARACEAE) en pacientes con VIH/SIDA. Perú, 2002.

ISMAEL, F. C. M.; LEITE, J. C. A.; SILVA, K. B. da. Proposta de um plano de recuperação para a área do lixão em pombal-pb. Intensa: Informativo Técnico do Semiárido, v. 7, n. 1, p. 01-09, 2013.

KUMARI, A.; PANDEY, V. C.; RAI, U. N. Feasibility of fern thelypteris dentata for revegetation of coal fly ash landfills. Journal of Geochemical Exploration, Elsevier, v. 128, p. 147-152, 2013. 
LIMA et al. Estudo de impacto ambiental: projeto de implantação para a ampliação do aterros sanitário metropolitano de Caucaia-CE. EIA/SEMACE, Fortaleza, 2011.

LONDE, P. R.; BITAR, N. A. B. Importância do uso de vegetação para contenção e combate à erosão em taludes do lixão desativado no município de Patos de Minas (MG). Revista Perquirere, Patos de Minas, v. 9, n. 2, 2011.

LORENZI, H. Árvores brasileiras: manual de identificação e cultivo de plantas arbóreas nativas do Brasil. Nova Odessa: Instituto Plantarum, 1998. v. 2.352 p.

LORENZI, H.; MATOS, F. J. Plantas medicinais no Brasil: nativas e exóticas. 2. ed. Nova Odessa: Instituto Plantarum, 2008. 544 p.

LOVERA, A.; BONILLA, C.; HIDALGO, J. Efecto neutralizador del extracto acuoso de dracontium loretense (JERGÓN SACHA) sobre la actividad letal del veneno de bothrops atrox. Revista Peruana de Medicina Experimental y Salud Pública, Instituto Nacional de Salud, v. 23, n. 3, p. 177-181, 2006.

MADALENO, I. M. Plantas da medicina popular de São Luís, Brasil. Boletim do Museu Paraense Emílio Goeldi. Ciências Humanas, Museu Paraense Emílio Goeldi, v. 1, n. 1, p. 273-286, 2011.

MAROUELLI, W.; SILVA, H. da; LOPES, J. Irrigação na cultura da bucha vegetal. Embrapa Hortaliças-Circular Técnica (INFOTECA-E), Brasília, DF: Embrapa Hortaliças, p. 12, 2013.

MEINERZ, C. C. et al. Estudo de caso para recuperação paisagística do aterro sanitário de toledo-PR. Internacional Workshop, São Paulo, 2009.

\section{MINISTRY OF ENVIRONMENT OF THE} BRITISH COLUMBIA. Landfill gas management facilities design guidelines. Canada: Prepared by Conestoga-Rovers \& Associates, Richmond, British Columbia, 2010. 230 p.

OLIVEIRA, C. N. Recuperação ambiental de aterros sanitarios na região metropolitana de Campinas: revegetação e uso futuro. 88 p. Dissertação (Mestrado em Engenharia Civi) - Universidade Estadual de Campinas, Campinas, 2004.
RAHMAN, M. L.; TARRANT, S.; MCCOLLIN, D.; OLLERTON, J. Plant community composition and attributes reveal conservation implications for newly created grassland on capped landfill sites. Journal for nature conservation, Elsevier, v. 21, n. 4, p. 198-205, 2013.

RESENDE, L. A. de; PINTO, L. V. A.; SANTOS, E. C. dos; SILVA, S. Crescimento E Sobrevivência De Espécies Arbóreas Em Diferentes Modelos De Plantio Na Recuperação De Área Degradada Por Disposição De Resíduos Sólidos Urbanos1. Revista Árvore, v. 39, n. 1, p. 147-157, 2015. ISSN 0100-6762.

ROCHA, A. A.; OLIVEIRA, F. R. de; HUELSEN, M. G. V.; BORGES, W. R. et al. GPR 3D como método năo invasivo para estudo do crescimento e biomassa de raízes de árvores de florestas tropicais. In: V Simpósio Brasileiro de Geofísica, 5. Salvador: SBGI, 2012.

SANTANA, O. A.; ENCINAS, J. I. Levantamento das espécies exóticas arbóreas e seu impacto nas espécies nativas em áreas adjacentes a depósitos de resíduos domiciliares. Biotemas, v. 21, n. 4, p. 29-38, 2008.

SANTOS, G. O. Avaliação do cultivo de gramíneas na superfície de aterro sanitário, com ênfase para a redução da emissão de metano e dióxido de carbono para a atmosfera. 313 p. Tese (Doutorado em Saneamento Ambiental) — Pós-Graduação em Engenharia Hidráulica e Ambiental. Universidade Federal do Ceará, Fortaleza, 2012.

SOBRINHO, F. S. et al. Avaliação do potencial de propagação por sementes de capim-elefante hexaplóide. Revista Ciência e Agrotecnologia, Scielo, v. 32, n. 3, p. 974 - 977, 06 2008. ISSN 1413-7054.

SOCIEDADE BRASILEIRA DE BOTÂNICA DO BRASIL. Manual sobre métodos de estudo florístico e fitossociológico: ecossistema Caatinga. Brasília: SBB, 2013.

SOUTO, P. C.; SALES, F. C. V.; SOUTO, J. S.; SANTOS, R. V. dos; SOUSA, A. A. de. Biometria de frutos e número de sementes de calotropis procera (ait.) R. Br. no semi-árido da Paraiba. Revista Verde de Agroecologia e Desenvolvimento Sustentável, v. 3, n. 1, p. $108-113,2008$.

SOUZA, C. M. d. Recuperação de áreas degradadas em aterros sanitários. 51 p. - Monografia (Graduação em Engenharia Florestal), Universidade Federal Rural do Rio de Janeiro, Rio de Janeiro, 2007. 
UNITED STATES ENVIRONMENTAL

PROTECTION AGENCY - USEPA. Guidance

for evaluating landfill gas emissions from closed

or abandoned facilities. Office of Research and

Development,Washington, D.C., USEPA., 2005. 86 p.

XIAOLI, C.; ZIYANG, L.; SHIMAOKA, T.;

NAKAYAMA, H.; YING, Z.; XIAOYAN, C.;

KOMIYA, T.; ISHIZAKI, T.; YOUCAI, Z.

Characteristics of environmental factors and their

effects on $\mathrm{CH} 4$ and $\mathrm{CO} 2$ emissions from a closed

landfill: An ecological case study of Shanghai. Waste

Management, Elsevier, v. 30, n. 3, p. 446-451, 2010. 